http://jmscr.igmpublication.org/home/ ISSN (e)-2347-176x ISSN (p) 2455-0450

crossref DOI: https://dx.doi.org/10.18535/jmscr/v8i3.111

\title{
Gorlin Goltz Syndrome- Why Medical and Dental Practitioners Should Join Hands- A Case Report
}

\begin{abstract}
Authors
Geeti Vajdi Mitra ${ }^{1}$, Tejas Motiwale ${ }^{2}$, Aditi Bardia Ghorawat ${ }^{3 *}$

${ }^{1}$ Professor and Head, Department of Oral and Maxillofacial Surgery, Sri Aurobindo College of Dentistry and P.G. Institute, Indore

${ }^{2}$ Professor, Department of Oral and Maxillofacial Surgery, Sri Aurobindo College of Dentistry and P.G. Institute, Indore

${ }^{3}$ Post Graduate Student, Department of Oral and Maxillofacial Surgery, Sri Aurobindo College of Dentistry and P.G. Institute, Indore

*Corresponding Author

Dr Aditi Bardia Ghorawat

Abstract

Background: Nevoid basal cell carcinoma syndrome (NBCCS), popularly known as Gorlin Goltz syndrome, is an autosomal dominant hereditary disorder encompassing various developmental abnormalities and neoplasms. It is frequently detected by maxillofacial surgeons owing to the presence of jaw cyst, however a multidisciplinary approach is never taken.

Case Presentation: Case report of a patient with a characteristic habitus, in which Odontogenic Keratocyst served as an alarm bell for suspecting a syndromic condition, Gorlin Goltz Syndrome. The patient was treated for her Odontogenic Keratocyst and underwent a complete physical check-up from various specialties for early diagnosis of other lesions and existing comorbidities.

Conclusion: Gorlin \& Goltz ${ }^{[1]}$ described the classical triad composed of multiple basal cell carcinoma, odontogenic keratocyst $(O K C)$ in the jaws and bifid ribs that characterized the diagnosis of this syndrome. It has been our attempt to provide the patient with a holistic, multidisciplinary approach.
\end{abstract}

\section{Introduction}

Head and neck pathologies do not always present in isolation, they could be associated with a syndromic condition. Odontogenic Keratocyst is defined as "a benign uni- or multicystic, intraosseus tumour of odontogenic origin, with a characteristic lining of parakeratinized stratified squamous epithelium and potential for aggressive, infiltrative behavior". ${ }^{[2]}$

Gorlin Goltz is a rare phakomatoses caused by mutation in patched tumour suppressor gene
$(\mathrm{PTCH})$ on chromosome 9q22.3 with the incidence rate of 1 in 57000 to $256000 .^{[2]}$

Odontogenic Keratocyst (OKC) is an enigmatic developmetal odontogenic cyst of epithelial origin, first identified by Mikulicz in 1876; coined and described by Philipsen in $1956 .{ }^{[3]}$

In this article we will be reporting a case of this syndrome and its close association with various systemic and local clinical presentations. This case also discusses the multi-disciplinary approach towards providing quality of life for patients suffering from the same. 


\section{Case Report}

\section{Clinical Examination}

A patient, 16-year-old Indian girl was the first child of non-consanguineous parents. She has no family history of the disease She has a history of delayed milestones. Menarche was reported at the age of 16 years with regular cycles.

Patient reported to the Department of Oral and Maxillofacial Surgery, with the complaint of swelling over her mandibular anterior region for 1 month which gradually increased since its onset to attain the present size. The swelling was not associated with any other symptoms.

On clinical examination, the patient presented with $170 \mathrm{~cm}$ height (greater than normal), $40 \mathrm{~kg}$ weight, BMI of 14.2 (considered underweight), ectomorphic, with moderate nourishment. Features of scoliosis, mild kyphosis, and sprengel shoulderswere present. Circumference of head higher than average dimensions of head of Indian girls her age. (Fig1A,B,C)

Patient presented with hypertelorism, broad nasal bridge and prognathic mandible. Swelling on the left side of mandible thereby causing mild facial asymmetry. The skin over the swelling appears normal with no secondary changes. Examination of the extremities revealed multiple 1-2 mm brownish pits (Fig 2)

On intraoral examination, there was a bony hard swelling obliterating the left buccal vestibule caused by bucco-lingual cortical expansion in 42 to 34. The swelling was bony hard with crepitation noted on palpation 33 and 34 were tender on percussion. $31-32$ are distally tilted and 33 - 34 are mesially tilted. Diastema noted between 31 and 41. Bilateral crossbite noted with Angle's Class II malocclusion. Peg shaped lateral 22 present. (Fig. 3)

Fine needle aspiration yielded cheesy white aspirate which was sent for histopathological examination.

\section{Radiographic Examination}

Orthopantomograph revealed a well-defined ovalshaped radiolucency in 43 to 35 region with complete involvement of the alveolus in the supero-inferior aspect of the mentioned region with severe thinning of the inferior mandibular border. Roots of mandibular anterior teeth appear hanging in the radiolucent cavitation. Tilting of the teeth are in sync with the clinical finding. (Fig 4)

Chest $X$ ray revealed bifid ribs of $4^{\text {th }}$ and $5^{\text {th }}$ ribs on left side and scoliosis. (Fig 5)

Dorso-lumbar X ray revealed: scoliosis, convexity of dorsal spine towards right; loss of dorsal kyphotic curve alignment; normal intervertebral distance; normal size and shape of vertebrae; hypoplastic posterior end of $4^{\text {th }}$ rib on left side.

Lumbo-sacral Spine X-ray revealed: normal bilateral Sacro-iliac Joint; normal size, shape and density of vertebrae.

PA Skull revealed: normal size and shape of Sella; no radiological feature of increased intracranial tension; calcification of falx cerebri noted; radiolucent defects seen in calvaria. (Fig 6)

Ultrasonography: Right renal hypertrophy $13 \mathrm{~cm}$ length (normal adult length: $10-12 \mathrm{~cm}^{[4]}$ ). Empty left renal fossa is suggestive of left kidney agenesis.

Computed Tomography of upper half of skull: reveals calcification of falx cerebri; small bony defect in the parietal eminence; hyperpneumatization of frontal, sphenoidal, ethmoidal sinuses, seen more on the right side.

Odontogenic cysts and tumours like OKC, Ameloblastoma, Aneurysmal bone cyst, Odontogenic myxoma and central giant cell granuloma were considered as the differential diagnosis.

\section{Histopathological Examination}

The H\&E stained section revealed cystic space lined by 8-10 cell thick, corrugated hyper parakeratinized stratified squamous epithelium lacking rete ridges. The basal layer showed a characteristic tombstone pattern. The epithelium is separated from fibro-cellular connective tissues in most places.

\section{Treatment}

The lesions were better investigated by Computed Tomography radiographs before surgery. After 
obtaining written informed consent from parents for intervention, patient was taken up for marsupialization of the mandibular lesion.

Marsupialization was done since she was a young patient and mandibular preservation is recommended. Carnoy's solution was not used since the lingual alveolar wall was perforated.

The cystic cavity healed progressively and had a healthy mucosal bed which reduced the cystic cavity size consistently. Follow-up of 6 months was done at the time of writing this article.

Table I: Major and Minor Diagnostic Criteria of Gorlin Goltz Syndrome

\begin{tabular}{|l|l|}
\hline MAJOR CRITERIA & MINOR CRITERIA \\
\hline Multiple BCC or one occurring under the age of 20 years & Macrocephaly determined after adjustment for height \\
\hline Histologically proven OKCs of the jaws & $\begin{array}{l}\text { Congenital malformation: Cleft lip or palate, frontal bossing, coarse face, } \\
\text { moderate or severe hypertelorism }\end{array}$ \\
\hline Palmar or plantar pits (three or more) & $\begin{array}{l}\text { Other skeletal abnormalities: Sprengel deformity, marked pectus deformity, } \\
\text { marked syndactyly of the digits }\end{array}$ \\
\hline Bilamellar calcification of the falx cerebri & $\begin{array}{l}\text { Radiological abnormalities: Bridging of the sella turcica, vertebral } \\
\text { anomalies such as hemivertebrae, fusion or elongation of the vertebral } \\
\text { bodies, modeling defects of the hands and feet or flame shaped lucency } \\
\text { hands or feet }\end{array}$ \\
\hline Bifid, fused or markedly splayed ribs & Medulloblastoma \\
\hline First degree relative with NBCCS & \\
\hline
\end{tabular}

Table II: Diagnostic Findings in Adults with Gorlin Goltz Syndrome

\begin{tabular}{|c|c|c|c|c|c|}
\hline$>50 \%$ frequency & & $15-49 \%$ frequency & & $<14 \%$ frequency & \\
\hline $\begin{array}{l}\text { Enlarged } \\
\text { circumference } \\
\text { frontal-parietal bossing) }\end{array}$ & + & $\begin{array}{ll}\text { 1. } & \text { Brain } \\
\text { asymmetry } & \text { ventricle }\end{array}$ & + & 1. Medullablastoma & $?$ \\
\hline 2. Multiple basal cell carcinomas & - & $\begin{array}{l}\text { 2. Calcification } \\
\text { tentorium cerebelli and } \\
\text { petroclinoid ligament }\end{array}$ & + & 2. True ocular hypertelorism & - \\
\hline 3. Odontogenic keratocysts of jaws & + & $\begin{array}{ll}\text { 3. } & \text { Calcified ovarian } \\
\text { fibromas } & \end{array}$ & - & 3. Meningioma & $?$ \\
\hline 4. Epidermal cysts of skin & - & $\begin{array}{l}\text { 4. Kyphoscoliosis or other } \\
\text { vertebral anomalies }\end{array}$ & + & 4. Lymphomesenteric cyst & $?$ \\
\hline 5. High-arched palate & - & 5. Lumbarization of sacrum & + & 5. Cardiac fibromas & $?$ \\
\hline 6. Palmar and/or plantar pits & + & 6. Short fourth metacarpals & - & 6. Fetal rhabdomyoma & $?$ \\
\hline $\begin{array}{l}\text { 7. Rib anomalies (splayed, fused, } \\
\text { partially missing, bifid, etc.) }\end{array}$ & + & $\begin{array}{lll}\text { 7. } & \begin{array}{l}\text { Narrow } \\
\text { shoulders }\end{array} & \text { sloping } \\
\end{array}$ & + & 7. Ovarian fibrosarcoma & - \\
\hline $\begin{array}{l}\text { 8. Spina bifida occulta of cervical or } \\
\text { thoracic vertebrae }\end{array}$ & - & 8. Prognathism & + & 8. Marfanoid build & + \\
\hline 9. Calcified falx cerebri & + & $\begin{array}{l}\text { 9. Pectus excavatum/ } \\
\text { carinatum }\end{array}$ & $?$ & 9. Anosmia & - \\
\hline $\begin{array}{l}\text { 10. Calcified diaphrgma sellae (bridged } \\
\text { sella, fused clinoids }\end{array}$ & + & $\begin{array}{l}\text { 10. Pseudocystic lytic lesion } \\
\text { of bones (hamartomas) }\end{array}$ & $?$ & 10. Agenesis of corpus callosum & - \\
\hline $\begin{array}{l}\text { 11. Hyperpneumatization of paranasal } \\
\text { sinuses }\end{array}$ & + & 11. Strabismus (exotropia) & - & 11. Cleft lip and/or palate & - \\
\hline & & 12. Syndactyly & - & 12. Cyst of septum pellucidum & $?$ \\
\hline & & 13. Synphorys & - & 13. Low pitched female voice & - \\
\hline & & & & 14. Polydactyly, postaxial- hands and feet & - \\
\hline & & & & 15. Sprengel deformity of scapula & + \\
\hline & & & & 16. Vertebral body fusion & + \\
\hline & & & & $\begin{array}{l}\text { 17. Congenital cataract, glaucoma, } \\
\text { coloboma of iris, retina, optic }\end{array}$ & - \\
\hline
\end{tabular}

In Our Case Symptoms- (+): Present (-): Absent (?): Unknown/ Could Not Be Assessed 


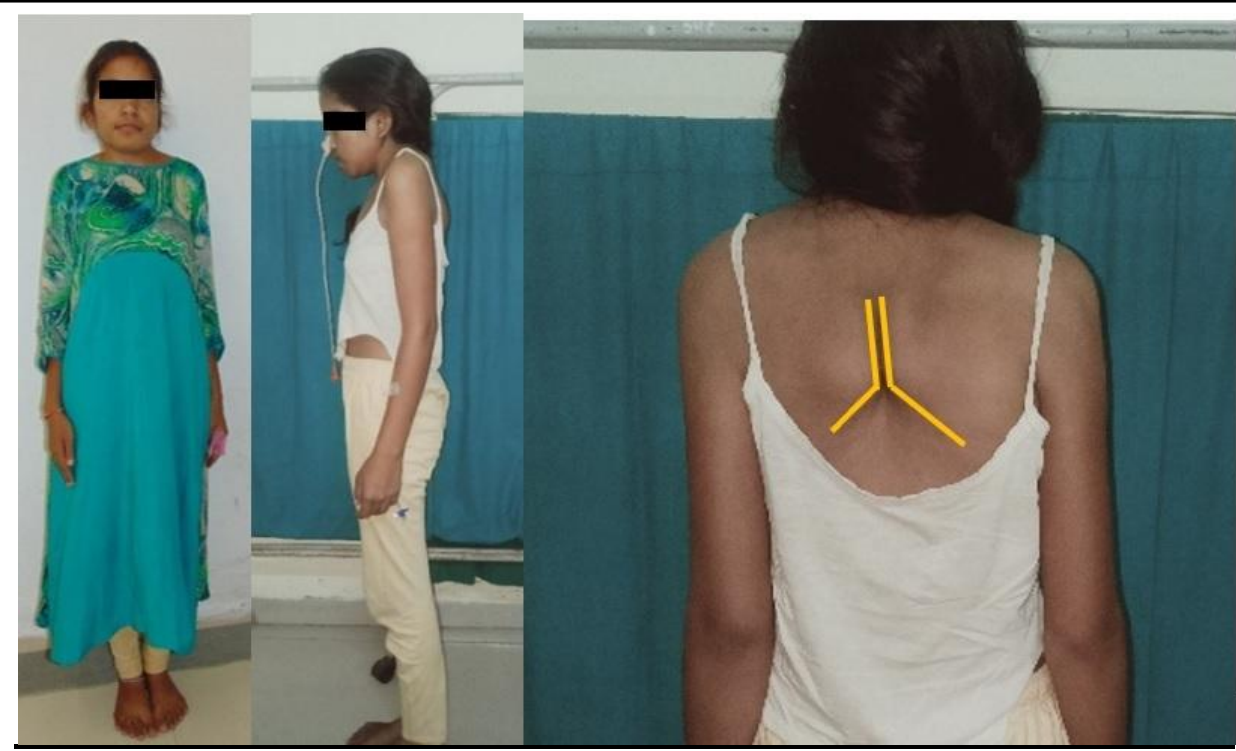

Fig 1 A. Ectomorphic build, height greater than average; BCRI. Kyphoscoliosis; C. Sprengel Shoulders

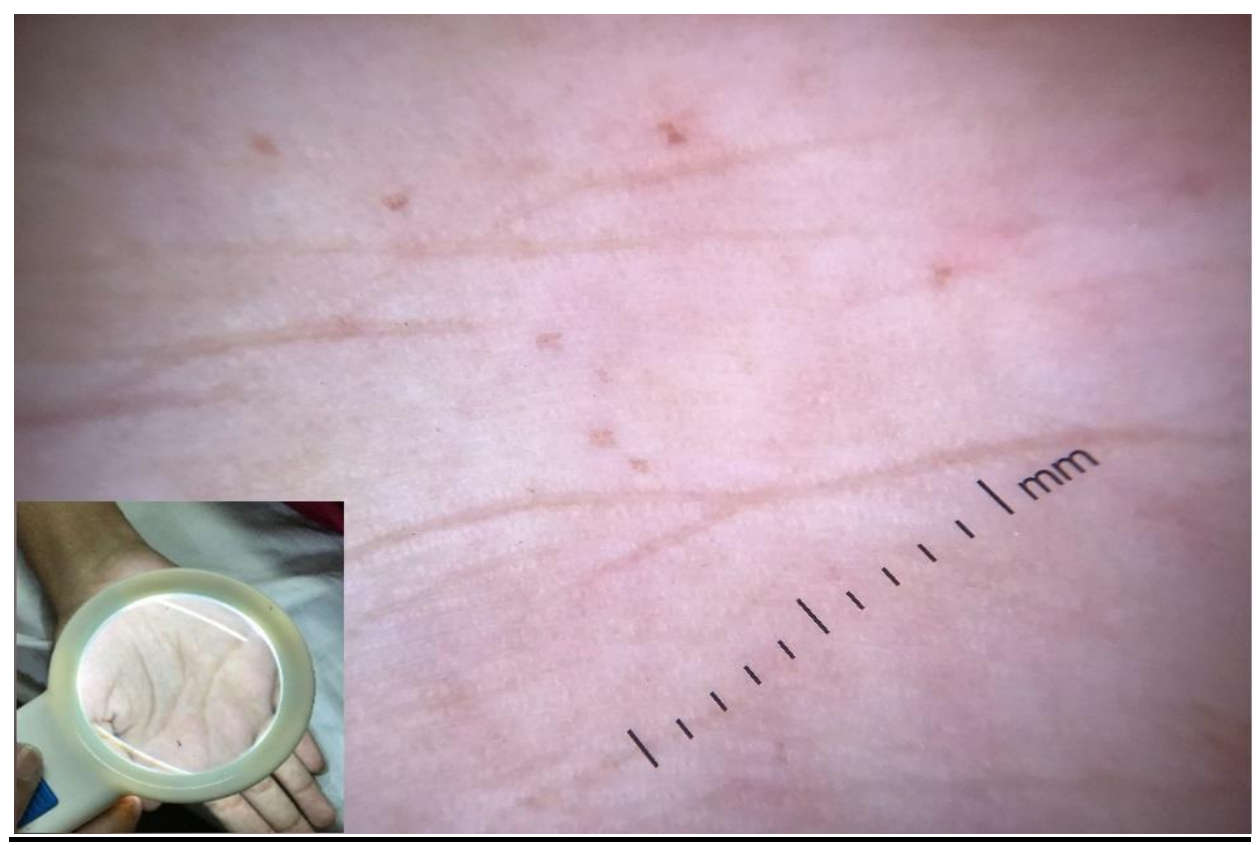

Fig 2 Palmar Pits

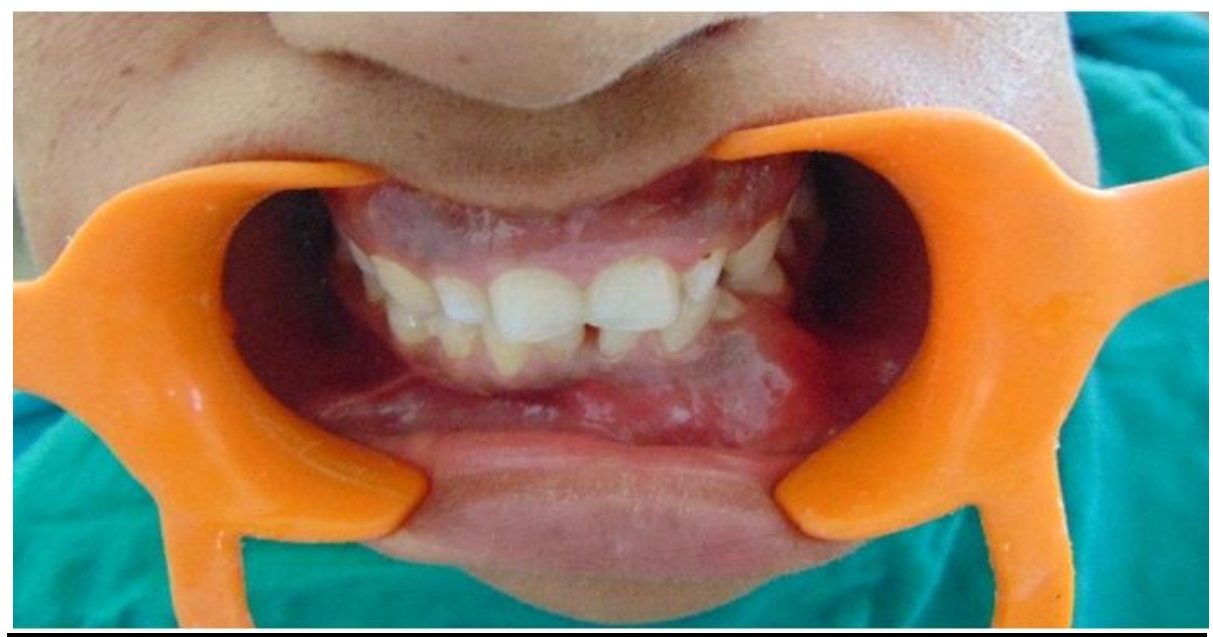

Fig 3 Intra-oral Examination reveals a bony hard swelling along left buccal vestibule 


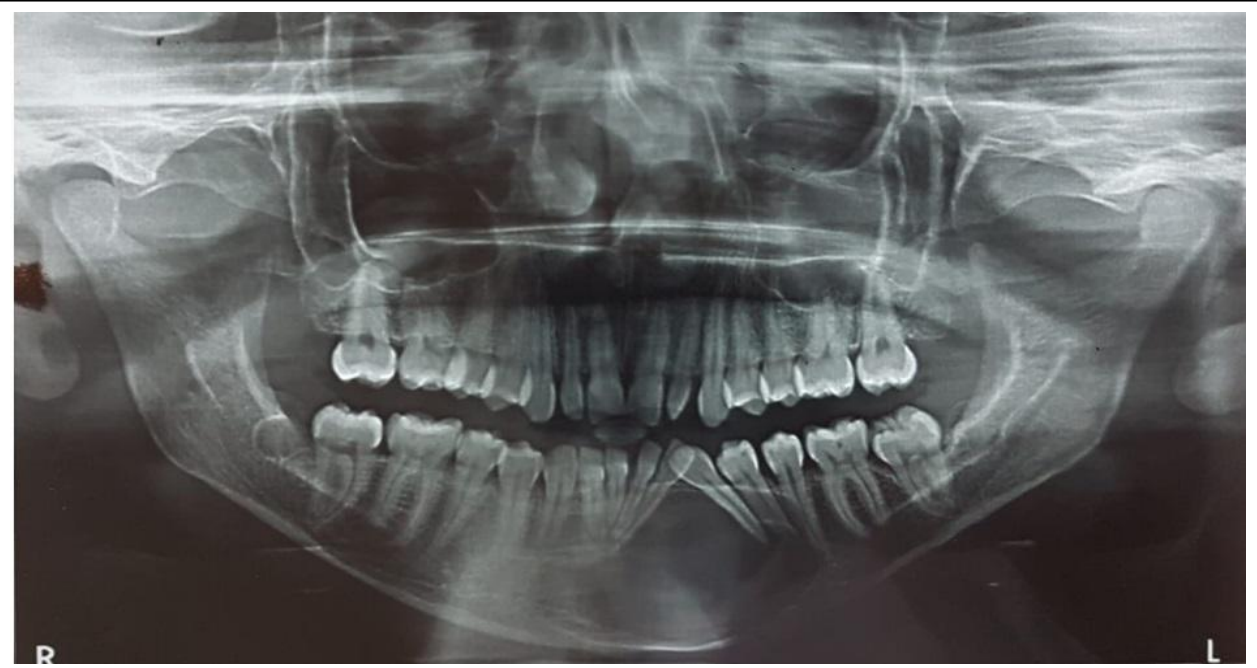

Fig 4 Orthopantomogram: well defined oval shaped radiolucency extending from 43 to 35

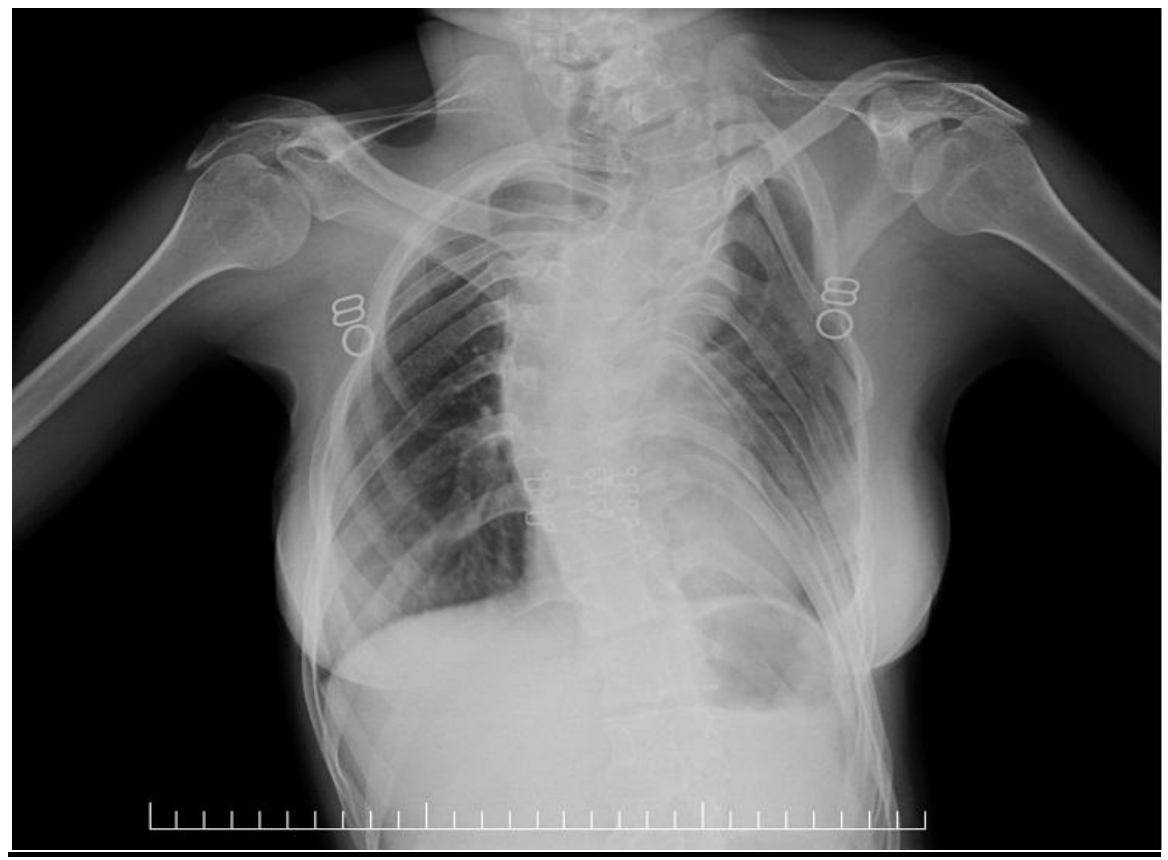

Fig 5 Chest $X$ ray reveals bifid ribs of $4^{\text {th }}$ and $5^{\text {th }}$ ribs on left side and scoliosis and cardiomegaly

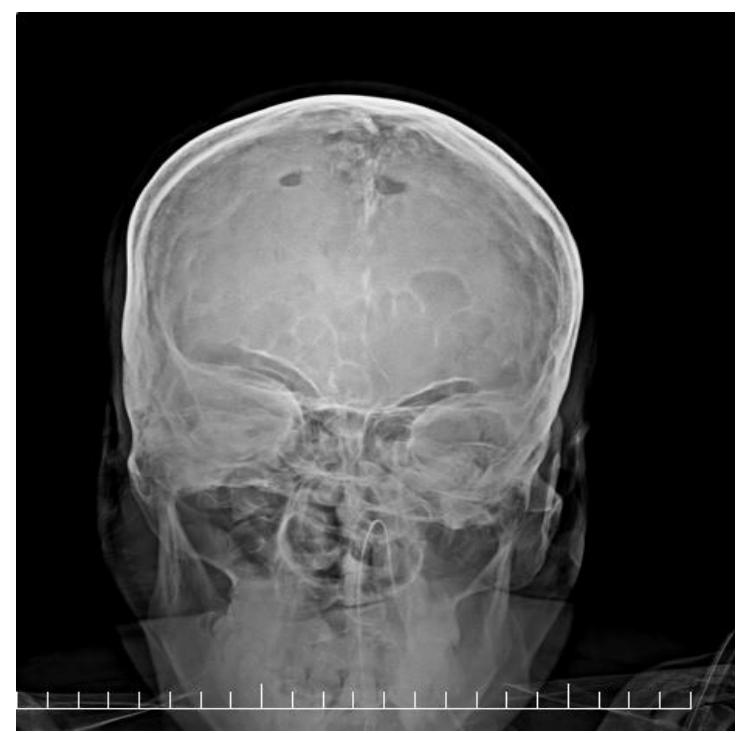

Fig 6. PA Skull reveals: normal size and shape of Sella; no radiological feature of increased intracranial tension; calcification of falx cerebri noted; radiolucent defects seen in calvaria. 


\section{Discussion}

Gorlin-Goltz syndrome is a genetic condition with autosomal dominant phenotype expressed variably. Patched tumour suppressor gene (PTCH), mapped onto 9q21-23 ${ }^{(1,4)}$ chromosome is influenced by Sonic Hedgehog (SHH). The Smo (Smoothened) protein is normally inhibited by PTCH-1, but due to SHH signalling pathway they lead to over activity of Smo, resulting in neoplastic activity. This same mechanism is considered a common genetic etiology for other benign tumours of the jaw.

Gorlin Goltz syndrome can be confirmed based on various diagnostic criteria as mentioned in Table II. These criteria were defined in 1993 by Evans et al and revised in 1997 by Kimonis et al. ${ }^{[5]}$ The presence of 2 major criteria or one major and 2 minor ones testifies the existence of Gorlin Goltz syndrome. (Table I). Histologically proven OKCs of jaw, palmar and plantar pits, calcification of falx cerebri, bifid ribs were all positive major criteria present in our patient, which is indicative of Gorlin Goltz syndrome in our patient. Additionally, multitude of symptoms (Table II) were observed in this case represented by (+) symbol in (Table II).

In Gorlin Goltz syndrome patients, Evans et al. (1993) noted overall frequency of $65 \%$ odontogenic keratocysts out of which, $90 \%$ were over 40 years and $30 \%$ were over 20 years. They peak during the second and third decades but continue to appear throughout life (Gorlin 1987, Chevenix-Trench et al. 1993). There is no racial predilection (Goldstein et al. 1994).

Such assortment of symptoms requires a multidisciplinary action, thus the management should include the following:

\section{Genetic Counselling}

At a genetic level the etiopathogenesis of the syndrome can be attributed to abnormalities in long arm of chromosome 9(q22.3-q31) and mutations in human patched gene (PTCH1 gene), sonic hedgehog (SHH). Thus, the patient's siblings and close relatives should be assessed and future offspring of the parents must be checked in utero. None of our patient's first degree relatives were affected by the condition

\section{Odontogenic Keratocysts}

For the surgical management of $\mathrm{OKC}$, in order to completely remove the disease, we must focus on both reducing the risk of recurrence whilst maintaining adjacent structures.

There continues to be two schools of thought in the surgical management of OKCs. Meiselmann advocates conservative treatment, whilst Madras and Lapointe are in favour of aggressive treatment based on $30 \%$ risk of recurrence of these tumours, when treated with enucleation alone. ${ }^{[6]}$ Stoelinga believes there could be extension and persistence in adjacent structures including soft tissues owing to its aggressive nature ${ }^{[7]}$, and the ability for ameloblastic or malignant transformation according to Williams and Connor ${ }^{[8]}$. Thus, a mechanical curettage, chemical curettage using modified Carnoy's solution, peripheral ostectomy and in some cases resection with a margin of normal tissue has been advocated by several authors. ${ }^{[8]}$. The disadvantages of an aggressive approach to treatment are irritation to surrounding mucosa, loss of the involved teeth, paresthesia secondary to complete loss of sensation along inferior alveolar nerve distribution, facial disfigurement in case of large OKCs. Rehabilitation of oral functions with dental implants and prosthetic restoration after the cessation of the physical growth is recommended. Marsupialization was done since she was a young patient and mandibular preservation is recommended. Carnoy's solution was not used since the lingual alveolar wall was perforated. Patient has since been kept on close follow- up.

\section{Cutaneous Anomalies}

Patients with nevoid basal cell carcinoma syndrome must visit dermatologists at frequent intervals of 2-3 months, especially during adolescence. Earlier visits are indicated for the young child at risk. Various approaches used are surgical excision, curettage and electrodissection, Moh's micrographic surgery, cryosurgery, intralesional interferon alpha $2 \mathrm{~b}$, radiation 
therapy, $\mathrm{CO}_{2}$ laser vaporization, Nd:Yag Laser therapy, photodynamic therapy, cisplatindoxorubicin-radiation. ${ }^{[9]}$

In our patient, there were no symptoms associated with the palmar and plantar pits or milia noted thus no dermatological intervention was done.

Orthopaedics: Treatment of scoliosis is determined by the Cobb method. Orthosis in the form of Milwaukee or Boston brace is used in case of progressive curvature. L- rods are used for severe deformity corrections. For the treatment of Sprengel shoulders, Mears (2001) described a novel approach that included an oblique plane osteotomy of the scapular body, along with release of the long head of the triceps from the scapula. He reported a significant improvement in function following this procedure. ${ }^{[10]}$ Treatment plan of kyphosis includes medical management of pain, surgical correction of deformity to remove any neural compression. Kyphosis is treated by, Smith-Peterson, pedical subtraction osteotomies and vertebral column resection.

Our patient was planned for orthopaedic intervention after cessation of growth for signs of spregel shoulder and kyphoscoliosis.

Ophthalmic: Esotropia or strabismus is treated by anticholinesterase drops or ointments. Prednisone usage in endoscopic removal of orbital cysts is done.

No orbital signs could be established in our patient.

\section{Other Management}

Psychiatric consultation for learning disabilities. Definitive management for various neoplasms or hamartomas associated. Our patient is undergoing psychiatric treatment for her low intelligence quotient.

Neurological findings, brain tumours or seizures require definitive neurological intervention. Cardiac fibroma or ovarian fibromas if present would require adequate non-surgical/ surgical management.

Genito-urinary consultation since kidney agenesis or cysts or supplication of renal pelvis of ureters are a chance finding most of the time.

\section{Conclusion}

Gorlin-Goltz syndrome is a conglomerate of anomalies and as maxillofacial surgeons with chief interest on odontogenic keratocyst, we are often the first clinicians to diagnose the syndrome. Thus, it is our duty as health experts to focus on the management of all or most of the anomalies that the patient is suffering with.

\section{Grants/ Funding: None}

\section{References}

1. Gorlin RJ, Goltz RW. Multiple Nevoid Basal-Cell Epithelioma, Jaw Cysts and Bifid Rib: A Syndrome. N Engl J Med 1960;262(18):908-12.

2. Borgonovo AE, Di Lascia S, Grossi G, Maiorana C. Two-stage treatment protocol of keratocystic odontogenic tumour in young patients with Gorlin-Goltz syndrome: Marsupialization and later enucleation with peripheral ostectomy. A 5-year-follow-up experience. International Journal of Pediatric Otorhinolaryngology 2011;75(12):1565-71.

3. Philipsen HP. Keratocyst (cholesteatomas) in the jaws. Tandlaegebladet 1956;(60): 963-80.

4. Hansen $\mathrm{K}$, Nielsen $\mathrm{M}$, Ewertsen $\mathrm{C}$. Ultrasonography of the Kidney: A Pictorial Review. Diagnostics 2015;6(1):2.

5. Kimonis VE, Goldstein AM, Pastakia B, Yang ML, Kase R, DiGiovanna JJ, et al. Clinical manifestations in 105 persons with nevoid basal cell carcinoma syndrome. Am J Med Genet 1997;69(3):299-308.

6. Madras J, Lapointe H. Keratocystic odontogenic tumour: reclassification of the odontogenic keratocyst from cyst to tumour. J Can Dent Assoc 2008;74 (2):165-165h.

7. Stoelinga PJW. Long-term follow-up on keratocysts treated according to a defined 
protocol. International Journal of Oral and Maxillofacial Surgery 2001;30(1):14-25.

8. Williams TP, Connor FA. Surgical management of the odontogenic keratocyst: aggressive approach. J Oral Maxillofac Surg 1994;52(9):964-6.

9. Kopera D, Cerroni L, Fink-Puches R, Kerl H. Different treatment modalities for the management of a patient with the nevoid basal cell carcinoma syndrome. Journal of the American Academy of Dermatology 1996;34(5, Part 2):937-9.

10. Mears DC. Partial resection of the scapula and a release of the long head of triceps for the management of Sprengel's deformity. J Pediatr Orthop 2001;21(2):242-5. 